\title{
Morfo-histologia do corpo gorduroso perivisceral em adultos de Hedypathes betulinus (Klug, 1825) (Coleoptera, Cerambycidae)
}

\author{
Fat body perviceral morphology in adults of Hedypathes betulinus (Klug, \\ I 825) (Coleoptera, Cerambycidae)
}

\author{
Rafael Alexandre Costa Ferreira' \\ Maria Eliza Miyoko Tomotake ${ }^{2(*)}$ \\ Helio Conte ${ }^{3}$
}

\section{Resumo}

\begin{abstract}
Nos insetos, o corpo gorduroso pode ser considerado um centro de metabolismo intermediário e também o local de síntese de alguns componentes da hemolinfa. Com objetivo de obter maiores informações sobre essa estrutura, foi realizado um estudo para a sua caracterização morfológica em adultos de Hedypathes betulinus Klug. Os resultados mostram que a estrutura ocorre em duas porções, a primeira, aderida ao trato digestivo e a segunda, associada ao tegumento, denominando-se, corpo gorduroso perivisceral e parietal, respectivamente. Histologicamente o corpo gorduroso apresenta dois tipos celulares, os trofócitos e os enócitos. Os trofócitos apresentam na área citoplasmática, vacúolos, núcleos esféricos, cromatina granular com variações na condensação, e em alguns casos, foram observados núcleos deslocados para a periferia celular. A presença de nucléolos múltiplos em algumas células sugere alta atividade nuclear. Os enócitos foram observados associados aos trofócitos, com núcleos centrais de formato esférico e cromatina de aspecto granular dispersa; os nucléolos apresentaram-se proeminentes em número variável e diferem dos trofócitos pela ausência de vacúolos, citoplasma granular, formato e tamanho das células.
\end{abstract}

Palavras-chave: broca; Ilex paraguariensis; enócitos; trofócitos.

I MSc.; Biólogo; Doutorando em Biologia Celular e Molecular na Universidade Estadual Paulista "Júlio de Mesquita Filho", UNESP; Rio Claro, São Paulo, Brasil; E-mail: rafaelalexferreira@gmail.com

2 Dra.; Bióloga; Professora Associada do Departamento de Ciências Biológicas da Universidade Estadual do Centro-Oeste, UNICENTRO; Núcleo de Pesquisas Ambientais, NPA; Endereço: Rua Simeão Camargo Varela de Sá, 03, CEDETEG, CEP:85.040-080, Guarapuava, Paraná, Brasil; E-mail: tomotake@unicentro.br (*) Autora para correspondência.

3 Dr.; Biólogo; Professor Associado do Departamento de Biologia Celular e Genética da Universidade Estadual de Maringá, UEM; Maringá, Paraná, Brasil; E-mail: hconte@uem.br

Recebido para publicação em 30/08/2010 e aceito em 27/09/20II

\begin{tabular}{llllll}
\hline Ambiência Guarapuava (PR) & v.7 n.3 & p. 489-499 & Set./Dez. 20II & ISSN I808 - 025I
\end{tabular}

DOI: 10.5777/ambiencia. 2011.03.07 


\section{Abstract}

In insects, the fat body may be considered a center of intermediary metabolism and also the site of synthesis of some components of the hemolymph. Aiming to obtain more knowledge about this structure, a study for characterization of morphological Hedypathes betulinus Klug was carried out. The results show that it takes place in two parts: the first one is adhered to the digestive tract, and the second one, associated with the coat, called the fat body and parietal perivisceral, respectively. Histologically the fat body is composed of two cell types, the trophocytes and the oenocites. The trophocytes present, in its cytoplasmic, vacuoles, spherical nuclei, granular chromatin with variations in condensation, and in some cases, it was observed nuclei displaced to periphery cells. The presence of multiple nucleoli in some cells suggests high nuclear activity. The oenocites were observed associated with trophocytes with central nuclei of spherical shape and granular appearance, dispersed chromatin, the nucleoli were prominent in variable number and differ from trophocytes by the absence of vacuoles, cytoplasm granular, shape and size of cells.

Key words: wood borer; Ilex paraguariensis; oenocites; trophocytes.

\section{Introdução}

A ordem Coleoptera, considerada a maior ordem dos insetos, contém cerca de $40 \%$ das espécies da classe Insecta. Dentre essa ordem, destaca-se a família Cerambycidae, comumente conhecidos como serradores, que no Brasil são representados por três subfamílias: Prioninae, Lamiinae e Cerambycinae. Hedypathes betulinus (Klug) é um representante da subfamília Cerambycinae e está presente em toda a América do Sul, seguindo a distribuição de seu hospedeiro principal, a erva-mate (Ilex paraguariensis St. Hil.) (MARTINS, 1999).

H. betulinus é comumente conhecido, no Brasil, como broca-da-erva-mate ou corintiano, por sua coloração preta e branca. Os danos mais severos, na erva-mate, são ocasionados pelas larvas, que durante o processo de alimentação, constroem galerias nos troncos e nas raízes das erveiras, dificultando a circulação de seiva e debilitando a planta. Os adultos alimentam-se da casca dos ramos, ocasionalmente anelando-os o que determina que estes murchem e caem, $o$ mesmo ocorre quando os insetos alimentamse dos pecíolos das folhas. O acúmulo de danos provoca perda de produção, morte das plantas jovens e/ou deteriorização das plantas adultas (CASSANELLO, 1993; GALILEO et al., 1993; MALLMAN et al., 2001).

$\mathrm{O}$ excesso de alimento ingerido pelos insetos durante a fase larval fica armazenado em um tecido denominado corpo gorduroso, sendo este o principal órgão do metabolismo intermediário, responsável pela síntese e pelo fornecimento da maioria dos componentes da hemolinfa, além de ser o principal local de armazenamento de reservas, como lipídios, carboidratos e proteínas, que são mobilizados durante a metamorfose, o vôo e a reprodução (CRUZ-LANDIM, 2009).

O corpo gorduroso é um órgão amorfo, formado por um conjunto de células que constituem camadas e/ou lóbulos. Essas estruturas estão suspensas na hemocele pela lâmina basal, músculos e traquéias, e estão em 
contato direto com a hemolinfa, o que facilita o intercâmbio de substâncias com os demais órgãos (KILBY,1963; PRICE, 1973; DEAN et al., 1985, CHAPMAN 1998, CONTE, 1994; ROMA, 2007; MARTINS, 2008; CRUZ-LANDIM, 2009).

Geralmente o corpo gorduroso é subdividido em parietal e perivisceral. A porção parietal é formada por uma massa celular localizada imediatamente abaixo da epiderme. A porção perivisceral é formada por uma massa celular que se dispõe em torno dos sistemas digestivo e reprodutor. Diferentes tipos celulares podem ocorrer, porém, os mais comuns são os trofócitos (ou adipócitos) e enócitos, funcionalmente diversificados e capazes de armazenar glicogênio, lipídeos e proteínas. (KILBY, 1963; LOCKE e COLLINS, 1966 e 1968; BUTTERWORTH et al., 1965; PRICE, 1973; WIGGLESWORTH, 1974; WOLFE et al., 1977; DEAN et. al., 1985; KEELEY, 1985; CHAPMAN, 1991; CRUZ-LANDIM e CONTE, 1992; CONTE, 1994; HAUNERLAND e SHIRK, 1995; CRUZ-LANDIM, 2004; ROMA, 2007; MARTINS, 2008; CRUZLANDIM, 2009).

Os trofócitos consistem em um agregado livre ou massas compactas de células, sendo as principais sedes do metabolismo intermediário dos insetos, por regular a composição do meio circulante do inseto, atendendo às necessidades metabólicas imediatas; desempenhar papel na vitelogenia e atuar nos processos de excreção e atuar na desintoxicação do organismo (WIGGLESWORTH, 1974; CRUZLANDIM, 1983 e 2004; CHAPMAN, 1991; CONTE e CRUZ-LANDIM, 1992).

Os enócitos são células de origem ectodérmica. Essa pode ser considerada a principal diferença em relação às demais células do corpo gorduroso, que são de origem mesodérmica. Mesmo com a sua origem distinta, os enócitos são considerados, na maioria dos trabalhos, como sendo células pertencentes ao corpo gorduroso, que em insetos adultos podem secretar hormônios, lipídeos e estar envolvidos nos processos de desintoxicação do inseto. (SNODGRASS, 1935; WIGGLESWORTH，1974; STOPPIE et al., 1981; JOHNSON e BATTERWORTH, 1985; CRUZLANDIM, 1983; DEAN et al., 1985; RUVOLO e CRUZ-LANDIM,1993; PAES DE OLIVEIRA, 2002; CONTE, 1994, ZARA e CAETANO, 2004; ROMA et al., 2005, ROLLO e CAMARGO-MATHIAS, 2006; ROMA et al., 2006; ROMA, 2007). Diante das informações a respeito do corpo gorduroso, seus componentes celulares e suas funções, o presente estudo teve por objetivos identificar, descrever e caracterizar morfo-histologicamente as células do corpo gorduroso perivisceral de adultos de Hedypathes betulinus (Klug, 1825) (Coleoptera, Cerambycidae) e fornecer subsídios para futuros trabalhos envolvendo esta espécie.

\section{Material e Métodos}

Foram realizadas coletas em ervais situados na região de Guarapuava (PR), durante o período de maior incidência da broca-da-erva-mate (setembro a maio). Os exemplares do inseto foram acondicionados em frascos plásticos e transportados para o Laboratório de Morfologia, do Núcleo de Pesquisas Ambientais - NPA/ UNICENTRO. Os insetos foram sexados, considerando características morfológicas externas, sendo que os machos apresentam 
as coxas mais desenvolvidas, extremidade da antena menos afilada e pigmentação das pernas mais acentuada em relação às fêmeas. Posteriormente os insetos foram acondicionados em gaiolas de vidro, com tampas perfuradas e mantidos em estufa do tipo BOD, em temperatura de $25 \pm 1$ ${ }^{\circ} \mathrm{C}$, umidade relativa de $80 \pm 10 \%$ e fotofase de onze horas simulando as condições ambientais do período de coleta, por um período de 24 horas.

\section{Morfologia do corpo gorduroso}

Os adultos de $H$. betulinus foram anestesiados por resfriamento e dissecados dorsalmente sob estereomicroscópio, sob aumento de 40x, em placa de Petri parafinada, contendo solução fisiológica para insetos ( $\mathrm{NaCl}, \mathrm{KH} 2 \mathrm{P} 4, \mathrm{NaHPO} 4$, pH 7,2). Após a dissecção, foram identificados o corpo gorduroso parietal e perivisceral. A camada perivisceral foi separada das demais estruturas, com auxílio de estiletes entomológicos, analisada e os registros fotográficos foram realizados em estereomicroscópio trinocular acoplado a uma máquina fotográfica digital, Olympus C-7070, no Núcleo de Pesquisas Ambientais NPA/UNICENTRO.

\section{Histologia do corpo gorduroso}

Para o estudo histológico, o corpo gorduroso perivisceral foi processado conforme Beçak e Paulete (1976) e Junqueira e Carneiro (1995).

O material foi fixado na mistura de Bouin aquoso (solução aquosa saturada de ácido pícrico, $30 \mathrm{ml}$; formalina, $10 \mathrm{ml}$; ácido acético glacial, $3 \mathrm{ml}$ ), por um período de 6 (seis) horas. Desidratado em série alcoólica crescente $(70 \%$ a $100 \%)$ e xilol. Inclusão em parafina histológica. Os cortes foram obtidos em Micrótomo Rotativo Leica RM 2145, com $5 \mu \mathrm{m}$ de espessura; corados em Hematoxilina de Harris e Eosina de Lison, passando em série alcoólica (100\% -70\%) e xilol; montados entre lâmina e lamínula com resina, para posterior observação e documentação fotográfica em Microscópio trinocular, acoplado a fotosistema digital Olympus C-7070 do Núcleo de Pesquisas Ambientais NPA/UNICENTRO em aumento de 400X e 1000X(imersão).

\section{Resultados e Discussão}

O corpo gorduroso de adultos machos e fêmeas de Hedypathes betulinus dispõese em duas camadas distintas, sendo a camada perivisceral associada ao trato digestivo e a camada parietal associada à cutícula. A sua coloração uniforme, branca e opaca, possivelmente deve-se à presença de reservas e a uma constituição mais complexa, levando à opacidade, semelhante ao proposto por Conte (1994), para larvas de Diatrea saccharalis, por Kilby (1963), para larvas de Calliphora e por Blissard (1982), para larvas de Trichoplusia ni.

Tanto em machos como em fêmeas, a camada parietal diferencia-se da perivisceral, por sua quantidade e disposição, assemelhando-se ao descrito por Sarmento et al. (2004), para adultos de Eriopis connexa (Coleoptera). A camada perivisceral mostrase formada por massas de células aderidas ao trato digestivo e ao sistema reprodutor, por meio de inúmeras traquéias, concordando com a morfologia descrita por Brown e Chippendale (1977), para larvas de Diatrea grandiosella, os quais associam a presença das traquéias aos processos oxidativos que ocorrem no corpo gorduroso. Nas fêmeas foi 
observada predominância (maior quantidade) de corpo gorduroso perivisceral, que pode estar associada à síntese de vitelogenia e à síntese de folículos ovarianos, como sugeridos por Johnson e Butterworth (1985) em adultos de Drosophila melanogaster.

Histologicamente o corpo gorduroso perivisceral em $H$. betulinus mostrou-se constituído por dois tipos celulares, os trofócitos e os enócitos, como observado em adultos de $D$. melanogaster por Johnson e Butterworth (1985), em larvas de Apis mellifera; em Melipona quadrifasciata, por Cruz-Landim (2004) e em adultos de E. connexa, por Sarmento et al. (2004), para os quais os trofócitos apresentam-se bem individualizados, com contornos celulares distintos.

Nos trofócitos de $H$. betulinus estão presentes vacúolos de localização e quantidades variáveis, bem como ocorrem coalescências entre esses vacúolos, formando assim um vacúolo único. Porém, Dutkowski (1974) sugere que os trofócitos do corpo gorduroso contêm inúmeros tipos de vacúolos e compartimentos, originados em geral da membrana plasmática. Essa variação, nos tipos de vacúolos, foi sugerida por Locke (1984) para Calpodes ethlius, constatando onze vacuolares diferentes. A presença dos vacúolos e processos de coalescência entre esses sugerem que seu conteúdo possa ser absorvido na hemolinfa, provavelmente por endocitose, quando pequenas vesículas são incorporadas para o interior dos trofócitos e os vacúolos coalescentes formam-se pela fusão de pequenos vacúolos ou provacúolos, semelhante ao descrito por Conte (1994) para larvas de D. saccharalis e para adipócitos de C. ethlius, por Locke (1984) (Figura 1A, $1 \mathrm{~B}, 1 \mathrm{C})$. Além dos vacúolos, observou-se a presença de grânulos de tamanhos variados, os quais muitas vezes mostram-se distintos e corados com intensidade. Muitos desses grânulos localizam-se ao redor dos vacúolos e núcleos.

Os núcleos dos trofócitos não apresentam localização fixa, sendo vistos em regiões centrais e, em algumas vezes, deslocados para regiões periféricas. Núcleos observados nas regiões centrais mostram forma esférica e quando periféricos, apresentam-se poligonais ou ramificados, semelhante ao descrito por Conte (1994), em larvas de D. saccharalis, tanto em núcleos centrais quanto nos periféricos, onde uma variação no número de nucléolos presente também foi observada em Trichplusia ni por Blissard (1982) (Figura 1D, 1E).

Os enócitos presentes no corpo gorduroso de $H$. betulinus apresentam-se como células grandes, de contornos bem definidos, núcleos com numerosos nucléolos e cromatina dispersa e citoplasma com granulações acidófilas, diferentemente ao observado por Cruz-Landim (2004) em larvas de Apis mellifera e Melipona quadrifasciata, nas quais os enócitos mostram grânulos basófilos. Ainda, segundo Cruz-Landim (2004), esse tipo celular pode apresentar morfologia diferenciada, em que o tamanho celular e seus contornos eventualmente mostram-se irregulares. Embora com pouca frequência, vacúolos podem aparecer em seu citoplasma (Figura 1F).

A presença de um único tipo de enócito associado aos trofócitos do corpo gorduroso de $H$. betulinus, apresenta uma configuração semelhante ao observado em Diptera (EVANS, 1967; TOBE et al., 1970; THOMPSEN e THOMPSEN, 1974). Contudo, Locke (1969) menciona três tipos morfológicos de enócitos, mas nenhum associado aos trofócitos. 

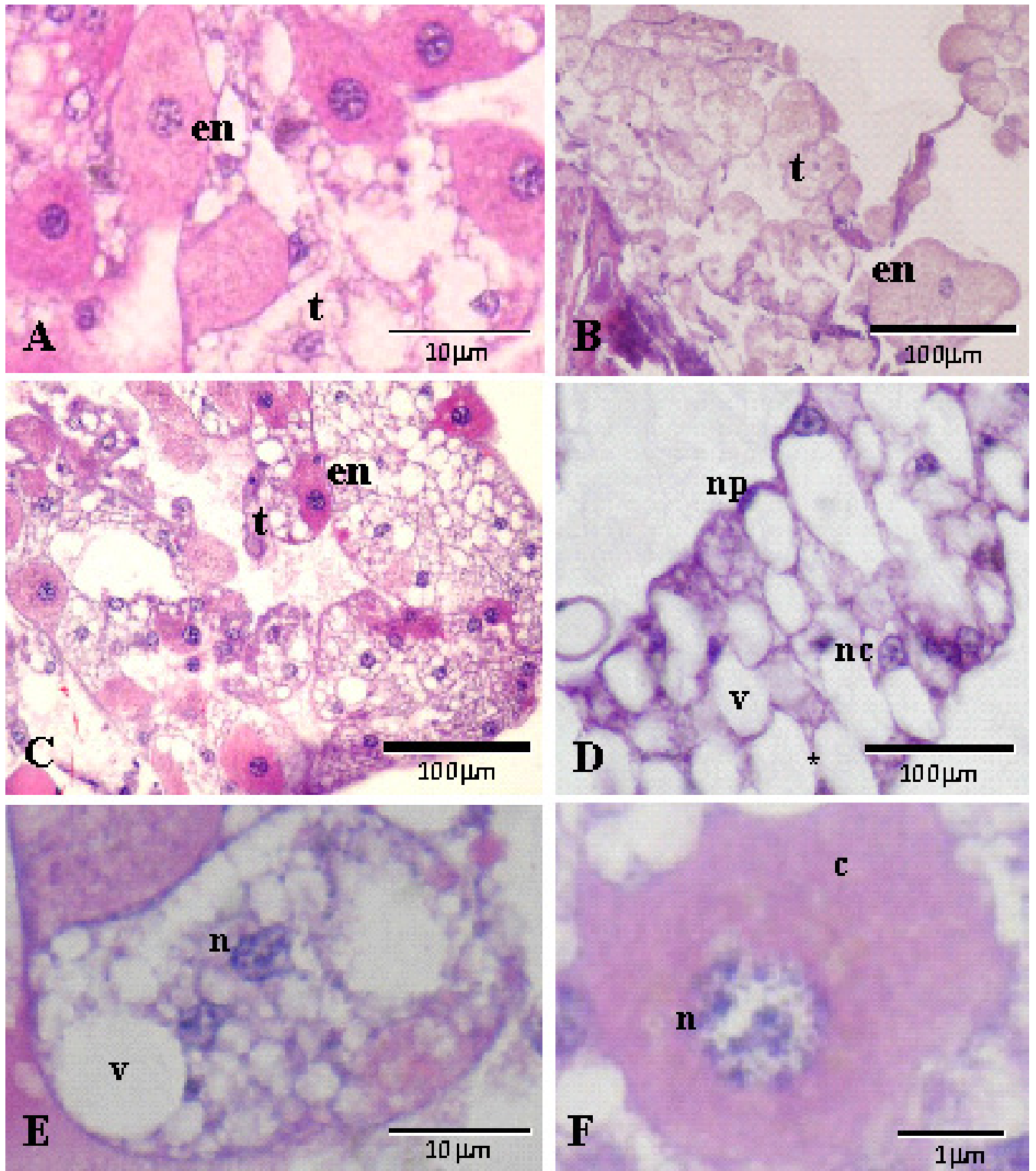

Figura I. Corpo gorduroso perivisceral de adultos de Hedypathes betulinus observado por microscopia de luz, corados com Hematoxilina/Eosina

A. Detalhe da distribuição do corpo gorduroso na hemocele de fêmea mostrando os enócitos (en) e trofócitos (t).

B. Corpo gorduroso de macho mostrando disposição dos enócitos (en) e trofócitos (t), na hemocele.

C. Corpo gorduroso periférico, mostrando a disposição de enócitos (en) associados a trofócitos (t)

D. Trofócitos mostrando vacúolos coalescentes (*) e posição dos núcleos periférico (np) e núcleo central (nc).

E. Detalhe de um trofócito mostrando núcleo (n) e vacúolos de reserva (v).

F. Enócito associado a trofócitos mostrando citoplasma (c) e núcleo esférico, não encoberto e não comprimidos (n). 
Os estudos histológicos realizados para esta espécie não mostraram evidências de divisões celulares nos trofócitos e, portanto, o grande aumento na extensão do corpo gorduroso deve ocorrer por aumento do tamanho celular, semelhante ao descrito por Goiten (1989), para o corpo gorduroso de Apis mellifera.

\section{Conclusão}

A morfologia do corpo gorduroso perivisceral de adultos de $H$. betulinus, assemelha-se ao descrito para insetos em geral, é composto por dois tipos celulares, trofócitos e enócitos. Os enócitos foram observados associados aos trofócitos em quantidades variáveis entre machos e fêmeas. A literatura mostra divergências nas funções desenvol- vidas por este tipo celular, dentre elas, o envolvimento dessas células nos processo de vitelogenia, e neste aspecto, observou-se para $H$. betulinus, que as fêmeas apresentam quantidade deste tipo celular superior ao encontrado nos machos, podendo sugerir que esse tipo celular esta envolvido, também, nos processos reprodutivos. Espera-se que com a descrição morfológica do corpo gorduroso de H. betulinus apresentado neste trabalho, possa subsidiar outros estudos que possam elucidar questionamentos quanto ao manejo e controle desta espécie nas plantações, uma vez que sabido que o corpo gorduroso é responsável pelo metabolismo intermediário, por participar na síntese protéica e no armazenamento de lipídios e carboidratos, mostrando que podem participar de processos de desintoxicação e reprodução.

\section{Referências}

BEÇAK, W.; PAULETE, J. Técnicas de Citologia e Histologia. Rio de Janeiro: Livros Técnicos e Científicos, 1976.

BLISSARD, G. W. Cytology of fat body development in fifth instar larval of the cabbage looper, Thrichoplusia ni. Riverside: University of California, 1982.122p. Master of Science (Entomology).

BROWN, J. J.; CHIPPENDALE, G. M. Ultrastructure and respiration of the fat body of diapausing and non-diapausing larvae of the corn borer, Diatrea grandiosella. Journal of Insect Physiology, v.23, n. 9, p.1135-1142, 1977.

BUTTERWORTH, F. M.; BODENSTEIN, D.; KING, R. C. Adipose tissue of Drosophila melanogaster. I. An experimental study of larval fat body.Journal of Experimental Zoology, v.158, n.2, p.141-154, 1965.

CASSANELLO, A. M. L. Ciclo de vida e aspectos morfológicos de Hedypathes betulinus (Klug, 1825) (Coleoptera, Cerambycidae, Lamiinae), broca-da-erva-mate (Ilex paraguariensis St. Hil.). 1993.59f. Dissertação (Mestrado em Entomologia) - Universidade Federal do Paraná, UFPR, Curitiba, 1993.

CHAPMAN, R. F. General anatomy and function. In: The Insects of Australia. 2. ed. Carlton: Melbourne University Press, 1991. (CSIRO), p. 33-67. 
CHAPMAN, R. F. The insects: Structure and function. 4. ed. London: Cambridge Universities Press, 1998. 788 p.

CONTE,H.; CRUZ-LANDIM, C. Microscopia eletrônica de varredura do corpo gorduroso de Larvas de Diatraea Saccharalis (Lepidoptera, Pyralidae). Naturalia, São Paulo, v. especial, n. 09, p. 223-223, 1992.

CONTE, H.Morfologia do corpo gorduroso em larvas de Diatrea saccharlis (Lepidóptera: Pyralidae) não parasitadas e parasitas pelo Cotesia flavipes (Hymenoptera: Braconidae). 1994. 77f. Tese (Doutorado em Biologia Celular e Molecular) - Instituto de Biociências, Universidade Estadual Paulista, UNESP, Rio Claro, 1994.

CRUZ-LANDIM, C. O corpo gorduroso da larva de Melipona quadrifasciata anthidioides LEP (Apida, Meliponinae). Naturalia, São Paulo, v.8, [S.I.], p.7-23, 1983.

CRUZ-LANDIM, C. Biologia do desenvolvimento em abelhas. Departamento de Biologia, Instituto de Biociências, UNESP, 2004. Disponível em: <http://www.rc.unesp.br/ib/biologia/ carminda.html.html>. Acesso em: 20 dez. 2005.

CRUZ-LANDIM, C. Abelhões: morfologia e funções de sistemas. São Paulo: UNESP, 2009. $416 \mathrm{p}$.

DEAN, R. L.; LOCKE, M.; COLLINS, J. V. Structure of fat body. In: KERKUT, G.A.; GILBERT, L. I. Comprehensive insect physiology, biochemistry and pharmacology. Oxford: Pergamon Press, 1985. v.3, p.155-210.

DUTKOWSKI, A. B. Fat body of Galleria mellonella during metamorphosis. Cytochemical and ultrastructural studies. Folia Histochem Cytochem, Kraków, v.12, n. 3-4, p.269-280, 1974.

EVANS, J. J. T. Development and ultrastructure of the fat body cells and oenocytes of the Queensland fruit fly, Dacus tryoni (Frogg). Zeitschrift für Zellforschung, v.81, n.1, p.49$61,1967$.

GALILEO, M. H. M.; MARTINS, U. R.; MOURA, L. A. Sobre o comportamento, ontogenia e morfologia do aparelho reprodutor de Hedypathes betulinus (Klug, 1825) (Coleoptera, Cerambycidae, Lamiinae, Acanthoderini) a broca da erva-mate. Revista Brasileira de Entomologia, São Paulo, v.37, n.4, p.705-715, 1993.

GOITEN, M.R. C. Estudos morfológicos e morfométricos do corpo gorduroso e enócitos de Apis mellifera L. (Hymenoptera: Apidae) durante o desenvolvimento larval. 1989. 77f. Dissertação (Mestrado em Zoologia) - Instituto de Biociências, Universidade Estadual Paulista, UNESP, Rio Claro, 1989.

HAUNERLAND, N. H.; SHIRK, R. D. Regional functional differentiation in the insect fat body. Annual Review of Entomolody, v. 40, p. 121-145, 1995. 
JOHNSON, M. B.; BUTTERWORTH, F. M. Maturation and aging of adult fat body and oenocytes in Drosophila as reveled by light microscopic morphometry. Journal of Morphology, v.184, n.1, p.51-59, 1985.

JUNQUEIRA, L. C.; CARNEIRO, J. Histologia básica. 8. ed. Rio de Janeiro: Guanabara Koogan, 1995. 433p.

KEELEY, L. L. Structure of fat body. In: KERKUT, G. A.; GILBERT, L. I. Comprehensive Insect Physiology, Biochemistry and Pharmacology. Great Britian: Pergamon Press, 1985. v.3, p.211-248.

KILBY, B. A. Intermediary metabolism of the insect fat body. Arch. Insect Physiol., v.1, p.111-174, 1963.

LOCKE, M. The ultrastructural of the oenocytes in the molt/intermolt cycle of an insect. Tissue \& Cell, v.1, n.1, p.103-154, 1969.

LOCKE, M. The structure and development of the vacuolar system in the fat body of insects. In: KING, R.C.; AKAI, H. Insect Ultrastructure. New York: Plenum Press, 1984. p.151-197.

LOCKE, M.; COLLINS, J. V. Sequestration of protein by the fat body of an insect. Nature, v.210, n.5035, p.552-553, 1966.

LOCKE,M.; COLLINS,J.V.Protein uptake into multivesicular bodie and storange granules in the fat body of an insect. The Journal of Cell Biology, v.36, n.3, p.453-483, 1968.

MALLMANN, A. J.; SZEPANIUCK, A. M.; STERTZ, E.; MARMITT, L. A. Controle da broca da erva-mate através da galinha-d'Angola. Agroecologia e Desenvolvimento Rural Sustentável, Porto Alegre, v.2, n,3, p.13-17, 2001.

MARTINS, G.F.O corpogorduroso deAedes(stegomyia)aegypti(Diptera;Nematocera) (Linnaeus, 1762): estudo morfológico do orgão em diferentes idades e condições alimentares, isolamento, cultivo primário e transcriptoma dos enócitos.2008. 118 f. Tese (Doutorado em Ciências da Saúde) - Centro de Pesquisas René Rachou/Fiocruz, Belo Horizonte, 2008.

MARTINS, U. R. Coleoptera, Cerambycidae. In: BRANDÃO, C. R. F.; CANCELLO, E. M. (Ed.). São Paulo, Brasil: Síntese do conhecimento ao final do século XX. Invertebrados terrestres. São Paulo: BIOTASP/FAPESP, 1999. v.5, cap.13, p.123-132.

PAES DE OLIVEIRA, V.T. Ultra-estrutura do corpo gorduroso e desenvolvimento do ovário em rainhas operárias de Melipona quadrifasciata anthidioides Lep. 2002. $164 \mathrm{f}$. Dissertação (Mestrado em Ciências Biológicas) - Instituição de Biociências de Rio Claro, Universidade Estadual Paulista, Rio Claro, 2002. 
PRICE, G. M. Protein and nucleic acid metabolism in insect fat body. Biological Reviews, v.48, n.3, p.333-372, 1973.

ROMA, G. C. Análise morfológica comparativa da estrutura do corpo gorduroso nos Attini em diferentes níveis filogenéticos. 2007. 142f. Tese (Doutorado em Ciências Biológicas) - Instituto de Biociências, Universidade Estadual Paulista, UNESP, Rio Claro, 2007.

ROMA, G. C.; CAMARGO-MATHIAS, M.I.; BUENO, O. C. Fat body in some genera of leaf-cutting ants (Hymenoptera: Formicidae). Proteins, lipids and polysaccharides detection. Micron (Oxford 1993), New York, v. 37, p.234-242, 2006.

ROLLO, J. P.; CAMARGO-MATHIAS, M. I. Morphohistochemical characterization of the perivisceral fat body in royal worker female castes in different ages of Atta sexdens rubropilosa ants (Hymenoptera, Formicidae). Sociobiology, California, v.47, n. 2, p. 519-530, 2006.

RUVOLO-TAKASUSUKI, M. C. C.; CRUZ-LANDIM, C. Morphologic and morphometric aspects of oenocytes of Apis mellifera queers and workes in different phases of life. Memórias do Instituto Osvaldo Cruz, RIo de Janeio, v. 88, n. 3, p. 387395, 1993.

SARMENTO, R. de A.; OLIVEIRA, H. G. de; HOLTZ, A. M.; SILVA, S. M. da, SERRÃO, J. E.; PALLINI, A. Fat body morphology of Eriopsis connexa (Coleoptera, Coccinelidae) in function of two alimentary sources. Brazilian Archives of Biology and Techonology, Curitiba, v.47, n.3, p.407-411, 2004.

SNODGRASS, R. E. Principles of insect morphology. New York:Mc Graw- Hill Book, 1935.667p.

STOPPIE, P.; BRIERS, T.; HUYBRECHTS, R.; DE LOOF, A. Moulting hormone, juvenile hormone and ultrastucture of the fat body of adult Sarcophaga bullata (Diptera). Cell and Tissue Research, v.221, n.2, p.233-244, 1981.

THOMSEN, E.; THOMSEN, M. Fine structure of the fat body of the female Calliphora erythrocephla during the first egg-maturation cycle. Cell and Tissue Research, v.152, n.2, p.193-217, 1974.

TOBE, S. S.; DAVEY, K.G.; HUEBNER, E. Nutrient transfer during the reproductive cycle in Glossina austeni nerwst: Histology and histochemistry of the milk gland, fat body and oenocytes. Tissue \& Cell, v.5, n.4, p.633-650, 1970.

WIGGLESWORTH, V. B. The principles of insect physiology. New York: John Wiley, 1974. 827p. 
WOLFE, J.; AKAM, M. E.; ROBERTS, D. B. Biochemichal and immunological studies on larval serum protein. I. The major hemolymph proteins of Drosophila melanogaster third-instar larvae. The Federation of European Biochemical Societies Journal, v.79, n.1, p.47-53, 1977.

ZARA, F.J.; CAETANO, F.H. Ultramorphology and histochemistry of fat body cells from last instar larval of the Pachycondyla (=Neoponera) villosa (Fabricius) (Formicidae: Ponerinae). Brazilian Journal of Biology, São Carlos, v. 64, n. 3b, p. 725-735, 2004. 